\title{
Uso da somatotropina recombinante bovina em búfalas leiteiras II: metabolismos energético e mineral
}

\author{
[Use of recombinant bovine somatotropin (rbST) in dairy buffaloes II: energy and \\ mineral metabolism]
}

\author{
W.O. Melo ${ }^{1}$, A.S. Nascimento Júnior ${ }^{2}$, B. M. Monteiro ${ }^{1}$, J.D. Ribeiro Filho ${ }^{3}$, \\ C. Faturi ${ }^{2}$, L.C.C. Daher ${ }^{2}$, D.C. Souza ${ }^{4}$, E.M. Sousa ${ }^{5}$, \\ S.P. Faria Júnior ${ }^{6}$, R.B. Viana ${ }^{2}$ \\ ${ }^{1}$ Universidade Federal Rural da Amazônia - Paragominas, PA \\ ${ }^{2}$ Universidade Federal Rural da Amazônia - Belém, PA \\ ${ }^{3}$ Universidade Federal de Viçosa - Viçosa, MG \\ ${ }^{4}$ Universidade Estadual de São Paulo - Jaboticabal, SP \\ ${ }^{5}$ Secretaria Municipal de Saúde de Belém - Belém, PA \\ ${ }^{6}$ Gerente Técnico de Pecuária - Saúde Animal - São Paulo, SP
}

\begin{abstract}
RESUMO
Avaliou-se a influência da somatotropina recombinante bovina (rbST) sobre os metabolismos energético e mineral de búfalas entre 63e 154 dias em lactação. Foram utilizadas 22 búfalas, distribuídas em dois grupos experimentais: grupo rbST - aplicação de 500mg de rbST a cada 14 dias; grupo Controle - sem aplicação de rbST. A cada sete dias, foram coletadas amostras de sangue para a determinação do perfil bioquímico e mensuraram-se a produção de leite e o escore de condição corporal dos animais. As médias dos parâmetros estudados para os grupos rbST e Controle foram, respectivamente: produção de leite (PL): 6,44kg vs. 6,68kg; escore de condição corporal-ECC (1-5): 3,51 vs. 3,57; glicose: 70,58 vs. 64,81 mg/dL ( $\mathrm{P}=0,0003$ ); colesterol: 132,38 vs. 133,40mg/dL; triglicérides: 29,18 vs. 28,32mg/dL; proteína total: 8,57 vs. $8,75 \mathrm{~g} / \mathrm{dL}$; albumina: 3,47 vs. $3,60 \mathrm{~g} / \mathrm{dL}$; ureia: 32,46 vs. $33,86 \mathrm{mg} / \mathrm{dL}$; creatinina: 1,27 vs. $1,39 \mathrm{mg} / \mathrm{dL}$; cálcio:10,25 vs. 10,73mg/dL; fósforo:5,76 vs. $5,62 \mathrm{mg} / \mathrm{dL}$; e magnésio:3,70 vs. 3,70mg/dL. O uso de 500mg de rbSTinfluenciou o metabolismo da glicose, porém não modificou a PL, o ECC e os níveis dos demais parâmetros metabólicos estudados.
\end{abstract}

Palavras-chave: Bubalusbubalis, hormônio do crescimento, produção de leite, metabólito sanguíneo

\begin{abstract}
The aim was to evaluate the influence of recombinant bovine somatotropin (rbST) on the energy and mineral metabolism of buffaloes between $63-154$ days in milk. Twenty-two buffaloes distributed in two experimental groups were used: Group rbST $(n=11)$ - application of 500mg of rbST every 14 days; Control Group $(n=11)$ - no rbST. Every seven days, blood samples were taken to determine the biochemical profile, and milk production and body condition score were measured. The averages of the variables for rbST and Control groups were, respectively: milk yield $(M Y)-6.44 \mathrm{~kg} v \mathrm{v}$. $6.68 \mathrm{~kg}$; body condition score (BCS) - 3.51 vs $3.57(1-5)$; glucose -70.58 vs. $64.81 \mathrm{mg} / \mathrm{dL}(P=0.0003)$; cholesterol $132.38 \mathrm{vs} .133 .40 \mathrm{mg} / \mathrm{dL}$; triglycerides $-29.18 \mathrm{vs} .28 .32 \mathrm{mg} / \mathrm{dL}$; total protein $-8.57 \mathrm{vs} .8 .75 \mathrm{~g} / \mathrm{dL}$; albumin $3.47 \mathrm{vs} 3.60 \mathrm{~g} / \mathrm{dL}$; urea -32.46 vs $33.86 \mathrm{mg} / \mathrm{dL}$; creatinine $-1.27 \mathrm{vs} 1.39 \mathrm{mg} / \mathrm{dL}$; calcium - $10.25 \mathrm{vs}$. $10.73 \mathrm{mg} / \mathrm{dL}$; phosphorus - 5.76 vs $5.62 \mathrm{mg} / \mathrm{dL}$; and magnesium - $3.70 \mathrm{vs} 3.70 \mathrm{mg} / \mathrm{dL}$. Use of $500 \mathrm{mg} \mathrm{rbST}$ influenced glucose metabolism, but did not modify the MY, BCS and the levels of the other metabolic parameters studied.
\end{abstract}

Keywords:Bubalusbubalis, growth hormone, milk production, blood metabolites

Recebido em 1 de fevereiro de 2018

Aceito em 31 de agosto de 2018

E-mail: waldjaniomelo@zootecnista.com.br 


\section{INTRODUÇÃO}

Entre os procedimentos disponíveis no mercado para melhorar a eficiência e a rentabilidade das propriedades leiteiras,há o uso da somatotropina recombinante bovina ( $\mathrm{rbST}$ ), considerada uma biotecnologia alternativa que vem sendo muito difundida para aumentar a produção de leite e a persistência da lactação de vacas leiteiras de alta produção (Rodrigues, 2008).

Também conhecida como hormônio do crescimento (STH), a somatotropina é um hormônio pituitário que controla aspectos relacionados ao crescimento animal, ao metabolismo de nutrientes, além de afetar a função reprodutiva (Castigliegoet al., 2011). Seu mecanismo de ação envolve uma série de arranjos metabólicos no tecido animal, direcionando nutrientes para a glândula mamária, caracterizando-se como um excelente coordenador de nutrientes que aumenta a eficiência biológica para a síntese de leite (Bauman, 1992).

Os metabólitos sanguíneos têm sido utilizados principalmente como auxiliares do diagnóstico clínico, mas, a partir do surgimento do termo perfil metabólico, a bioquímica sanguínea passou a ser alvo de maior interesse na avaliação de rebanhos com diferentes índices produtivos e reprodutivos, indicando desequilíbrios nutricionais e metabólicos (Peixoto e Osório, 2007; Khan et al., 2011).

Estudos têm sido realizados para verificar a influência da somatotropina recombinante bovina sobre os metabolismos energético e mineral de bubalinos (Mishra e Shukla, 2004; Jabbaret al., 2007; Helal e Lasheen, 2008; Feckinghaus, 2009; Prasad e Singh, 2010).No entanto, os efeitos desse hormônio sobre a produção de leite, o ganho de peso e os perfis metabólico e mineral de búfalas em lactação ainda são muito variáveis e controversos, principalmente ao serem comparados com os efeitos já bem aclarados emvacas. Portanto, fazem-se necessárias pesquisas que descrevam a ação da rbST em búfalas leiteiras, não somente sobre a produção de leite, mas também a influência desse fármaco sobre osbiomarcadores dos metabolismos energético e mineral nessas fêmeas ao longo da lactação.
Acredita-se que a aplicação contínua de rbST ao longo da lactação aumenta a produção de leite das búfalas, alterando a proporção dos metabólitos energéticos e minerais sanguíneos. Dessa maneira, objetivou-se com este estudo quantificar os efeitos das aplicações de somatotropina recombinante bovina (rbST) sobre a produção de leite, o escore de condição corporal e os biomarcadores dos metabolismos energético e mineral durante a lactação de búfalas criadas nas condições do trópico úmido amazônico.

\section{MATERIAL E MÉTODOS}

O experimento foi aprovado pelo Comitê de Ética no Uso de Animais da Ufra, Protocolo 021/2016 (Ceua) - 23084.006670/2016-28 (Ufra), no qual se verificou que foram atendidas plenamente todas as exigências da Lei Federal 11.794/08 (Lei Arouca), sendo respeitados os Princípios Éticos da Experimentação Animal do Conselho Nacional de Controle de Experimentação Animal - Concea.

O experimento foi conduzido em uma fazenda localizada no município de Moju,mesorregião Nordeste do estado do Pará. O clima da região onde se localiza a propriedade em estudo é caracterizado como Ami (quente úmido), de acordo com a classificação de Köppen, com temperatura média anual entre 25 e $27^{\circ} \mathrm{C}$ e precipitação anual entre 2.000 e $3.000 \mathrm{~mm} / \mathrm{m}^{2}$, com distribuição irregular. A umidade relativa do ar é elevada, com índice de umidade relativa anual média de 77,9\% (Azevedo et al., 2011).

Foram utilizadas 22 búfalas adultas de diferentes grupamentos genéticos, mestiças, com predominância genética da raça Murrah (Bubalusbubalis). Todas as búfalas eram multíparas, lactantes com partos eutócicos, com $63 a 70$ dias em lactação (DEL) e 6,97 $\pm 1,55$ litros de leite por dia, em duas ordenhas diárias, escore corporal 3,31 (1-5) e peso corporal $513,17 \mathrm{~kg}$.

Os animais foram mantidos em lotação intermitente em Brachiaria (syn. Urochloa) humidicola(Quicuio da Amazônia), Brachiaria (syn. Urochloa) brizanthae Panicummaximumcv. Mombaça, recebendo água e sal mineral ad libitum. Adicionalmente às pastagens, as búfalas em lactação recebiam o quantitativo de $1 \mathrm{~kg}$ de ração/dia, constituída por $30,61 \%$ de torta de 
murumuru (Astrocaryummurumuru), 61,29\% de farelo de milho (Zeamays), 3,1\% de núcleo mineral e $5 \%$ de ureia.

A ração era constituída por $93,02 \%$ de matéria seca (MS), 8,41\% de matéria mineral (\%), $18,17 \%$ de proteína bruta (PB), $3,15 \%$ de extrato etéreo (EE), 23,9\% de fibra em detergente neutro (FDN) e 10,96\% de fibra em detergente ácido (FDA), obtida por meio da metodologia descrita por Silvae Queiroz (2002).

As búfalas foram distribuídas aleatoriamente em dois grupos experimentais: 11 búfalas que receberam a aplicação de 500mg de somatotrotopina bovina recombinante (grupo rbST; $2 \mathrm{~mL}$ de Boostin- MSD Saúde Animal) a cada 14 dias, por via subcutânea, na fossa ísquioretal, alternando-se os lados esquerdo e direito a cada aplicação, em um total de sete aplicações, sendo a primeira aos 63-70 dias em lactação e a última aos 147-154 dias em lactação; e11 búfalas que não receberam aplicação de rbST (grupo Controle).

As fêmeas eram ordenhadas manualmente, duas vezes ao dia, com intervalo médio de 12 horas entre as ordenhas. O controle da produção de leite foi realizado semanalmente, com esgota total prévia de 12 horas, nos intervalos 63-70; 77-84; 91-98; 105-112; 119-126; 133-140; e 147154 dias em lactação.

As amostras de sangue foram coletadas por punção da veia jugular externa, utilizando-se um sistema de coleta a vácuo, a cada sete dias, logo após a primeira ordenha (jejum de 12 horas), sendo as duas últimas coletas realizadas com intervalos de 14 dias. As amostras para determinação dos teores plasmáticos de glicose foram coletadas em tubos siliconados contendo fluoreto de sódio (tubos BD Vacutainer ${ }^{\circledR}$ Fluoreto/EDTA) e mantidas sob refrigeração até o processamento no laboratório. Para as demais análises, as amostras foram coletadas em tubos siliconados sem anticoagulante.

Para obtenção do plasma e do soro sanguíneos, as amostras foram centrifugadas por 15 minutos, a uma velocidade de $1.150 \mathrm{G}$, sendo a seguir separados por aspiração o plasma e o soro, respectivamente. As amostras foram aliquotadas e acondicionadas em freezer, a $-20^{\circ} \mathrm{C}$, para posterior análise.
As determinações da concentração plasmática de glicose, do colesterol, dostriglicérides, das proteínas totais séricas, da albumina sérica, da ureia sérica, da creatinina sérica, do cálcio sérico, do fósforo sérico e do magnésio sérico foram realizadas em analisador bioquímico automático HumaStar300 (HumaCount Plus - HumanGmbh, Max Planck-Rng21, Wesbaden - Alemanha) do Departamento de Veterinária da Universidade Federal de Viçosa.

Foram utilizados kits comerciais (InVitro Diagnóstica)para determinação da glicose plasmática (método GPO-PAP), do colesterol (método enzimático-colorimétrico com LCF), dostriglicérides (método GPO-PAP,enzimático colorimétrico c/ LCF), das proteínas totais séricas (método biureto), da albumina sérica (método verde de bromocresol- VBC), da ureia sérica (método enzimático colorimétrico GLDH), da creatinina sérica (método cinético colorimétrico (Jaffé), do cálcio sérico (método ocresolftaleína-complexona -CFC), do fósforo sérico (método fosfomolibdato UV), do magnésio sérico (método azul de xilidila).

O escore de condição corporal (ECC) dos animais foi estimado de acordo com Houghtonet al. (1990), modificado, acrescentando-se 0,5 unidade entre as mensurações, sendo 1 equivalente ao animal magro e 5 ao animal obeso. Todas as avaliações foram aferidas pelo mesmo examinador, a cada sete dias, durante o período experimental.

A estatística descritiva dos dados, representada pelas médias aritméticas e os desvios- padrão (DP) de cada tratamento, foi obtida pelo procedimento Meansdo programa SAS, versão 9.2 (SAS, 2008). Os testes de normalidade dos resíduos e a homogeneidade das variâncias de cada tempo foram realizados utilizando-se o Guide Data Analise do SAS. Os dados que não preencheram os pressupostos para a análise de variância (ANOVA) foram transformados em conformidade, de acordo com as sugestões do próprio programa.

A comparação entre as médias dos grupos dentro de cada tempo (trat/tempo) foi realizada por meio do teste de médias Tukey, mediante o comandoLeast Square Means (LSMeans) do SAS. Foi utilizado o nível de significância de 5\% para todos os testes realizados. 


\section{RESULTADOS E DISCUSSÃO}

Dentre as variáveis estudadas, verificou-se efeito significativo de tratamento (rbST) apenas para a glicose plasmática. Também foi observada interação entre o tratamento e o tempo na produção de leite e influência do tempo nos níveis de proteína total sérica, albumina sérica, ureia sérica, creatinina sérica, cálcio sérico e produção de leite (Tab.1).

Tabela 1. Média e desvio-padrão (DP) da produção de leite (kg), metabólitos sanguíneos e ECC (1-5) de búfalas tratadas com somatotropina recombinante bovina (rbST) ou não (controle) durante a lactação

\begin{tabular}{lccccccc}
\hline & \multicolumn{2}{c}{ Controle } & \multicolumn{3}{c}{ rBST } & \multicolumn{3}{c}{ P value } \\
\cline { 2 - 8 } & Média & DP & Média & DP & Tratamento & Tempo & Trat*Tempo \\
\hline Produção de leite, kg & 6,63 & 1,86 & 6,54 & 2,38 & 0,6219 & $<0,0001$ & 0,0053 \\
ECC, 1-5 & 3,57 & 0,40 & 3,51 & 0,34 & 0,6520 & 0,0921 & 0,0639 \\
Glicose, mg/dL & 64,75 & 7,45 & 69,97 & 9,06 & 0,0003 & 0,0166 & 0,1362 \\
Colesterol, mg/dL & 133,36 & 29,68 & 132,80 & 29,61 & 0,9196 & 0,6804 & 0,9389 \\
Triglicérides, mg/dL & 28,37 & 11,48 & 29,65 & 13,02 & 0,7695 & 0,0641 & 0,9496 \\
Proteína total, g/dL & 8,76 & 0,62 & 8,57 & 0,49 & 0,0998 & 0,0009 & 0,8664 \\
Albumina, g/dL & 3,60 & 0,44 & 3,48 & 0,41 & 0,5583 & $<0,0001$ & 0,1720 \\
Ureia, mg/dL & 33,79 & 11,19 & 32,35 & 11,68 & 0,7604 & $<0,0001$ & 0,5184 \\
Creatinina, mg/dL & 1,38 & 0,18 & 1,27 & 0,21 & 0,5194 & $<0,0001$ & 0,6411 \\
Cálcio, mg/dL & 10,73 & 1,37 & 10,31 & 1,08 & 0,0959 & $<0,0001$ & 0,4285 \\
Fósforo, mg/dL & 5,61 & 1,12 & 5,77 & 1,08 & 0,6529 & 0,4453 & 0,7894 \\
Magnésio, mg/dL & 3,70 & 0,13 & 3,70 & 0,16 & 0,9036 & 0,0034 & 0,4825 \\
\hline
\end{tabular}

Percebe-se, nos resultados avaliados, que não houve um efeito positivo da rbST na produção de leite das búfalas tratadas $(\mathrm{P}>0,05)$ (Fig.1; Painel A). Esses resultados são semelhantes aos obtidos por Jabbaret al. (2007), que verificaram o efeito do uso prolongado de rbST sobre a produtividade em búfalas da raça Nili-Ravi multíparas em lactação, distribuídas em três grupos: animais tratados com $250 \mathrm{mg}$ de rbST com intervalo de 14 dias; 36mg de rbST em dias alternados; e búfalas controle que não receberam rbST. Os autores não constataram diferença significativa na produção média de leite entre os tratamentos. Em contrapartida, as pesquisas de Jorge et al. (2002); Mishra e Shukla (2004); Helal e Lasheen (2008) descreveram aumentos significativos na produção de leite de búfalas tratadas com rbST.

Possivelmente, o não incremento significativo na produção de leite nas búfalas do presente experimento pode estar associado a alguns fatores, como o potencial genético do animal e o manejo nutricional, em que o fornecimento de concentrado era feito sem considerar a produção de leite, e isso pode ter inibido a resposta ao hormônio, conforme também observaram Santos et al. (2001) e Melo et al. (2013).

No presente estudo, não se observou efeito da aplicação de somatotropina recombinante bovina (rbST) no escore de condição corporal (ECC) de búfalas leiteiras, durante o período estudado ( $\mathrm{P}>0,05)$ (Tab.1). Esses resultados corroboram os obtidos por Feckinghaus (2009), que também não encontraram diferenças significativas no ECC de búfalas da raça Murrah entre animais tratados ou não com rbST.

O não efeito da administração da rbST no ECC pode estar associado ao status energético do animal, pois, segundo Lannaet al. (1995), quando a vaca se encontra em balanço energético positivo (BEP) no início do tratamento com rbST, há uma redução da síntese de lipídeos no tecido adiposo, aumentando a disponibilidade de substratos para suportar o aumento da produção de leite. Por outro lado, Bauman (1992) reporta que se a vaca se encontra em balanço energético negativo (BEN) ou próximo a zero quando o tratamento com rbST é iniciado, suas reservas corporais são mobilizadas para fornecer os nutrientes para a síntese adicional de leite, resultando em perda de condição corporal.

Com exceção da glicose, não foi observada qualquer influência darbST sobre a concentração plasmática dos metabólitos energéticos sanguíneos estudados. Durante o período do experimento, os teores de glicose (Fig.1; Painel B), colesterol (Fig.1; Painel C) e triglicérides (Fig.1; Painel D) no grupo tratado com 500mg de rbST ao longo da lactação variaram entre 64,50 e 
$80,33 \mathrm{mg} / \mathrm{dL} ; 114,80$ e $146,55 \mathrm{mg} / \mathrm{dL}$; e 21,00 e $42,00 \mathrm{mg} / \mathrm{dL}$, enquanto no grupo controle, oscilaram entre 57,50 e $74,56 \mathrm{mg} / \mathrm{dL} ; 128,40$ e $142,90 \mathrm{mg} / \mathrm{dL} ;$ e 22,20 e $37,36 \mathrm{mg} / \mathrm{dL}$, respectivamente.Esses resultados se assemelham com os obtidos por Helal e Lasheen (2008), que também não encontraram diferença significativa para os níveis de colesterol, mas observaram que as búfalas submetidas ao tratamento de $500 \mathrm{mg}$ de rbST tiveram acréscimo nos teores de glicose plasmática em relação aos animais do grupo controle. Já outros estudos não verificaram alteração nos teores de glicose e dos demais metabólitos energéticos em função da administração de rbST em búfalas leiteiras (Mishra e Shukla, 2004; Feckinghaus,2009; Kachiwalet al., 2015).

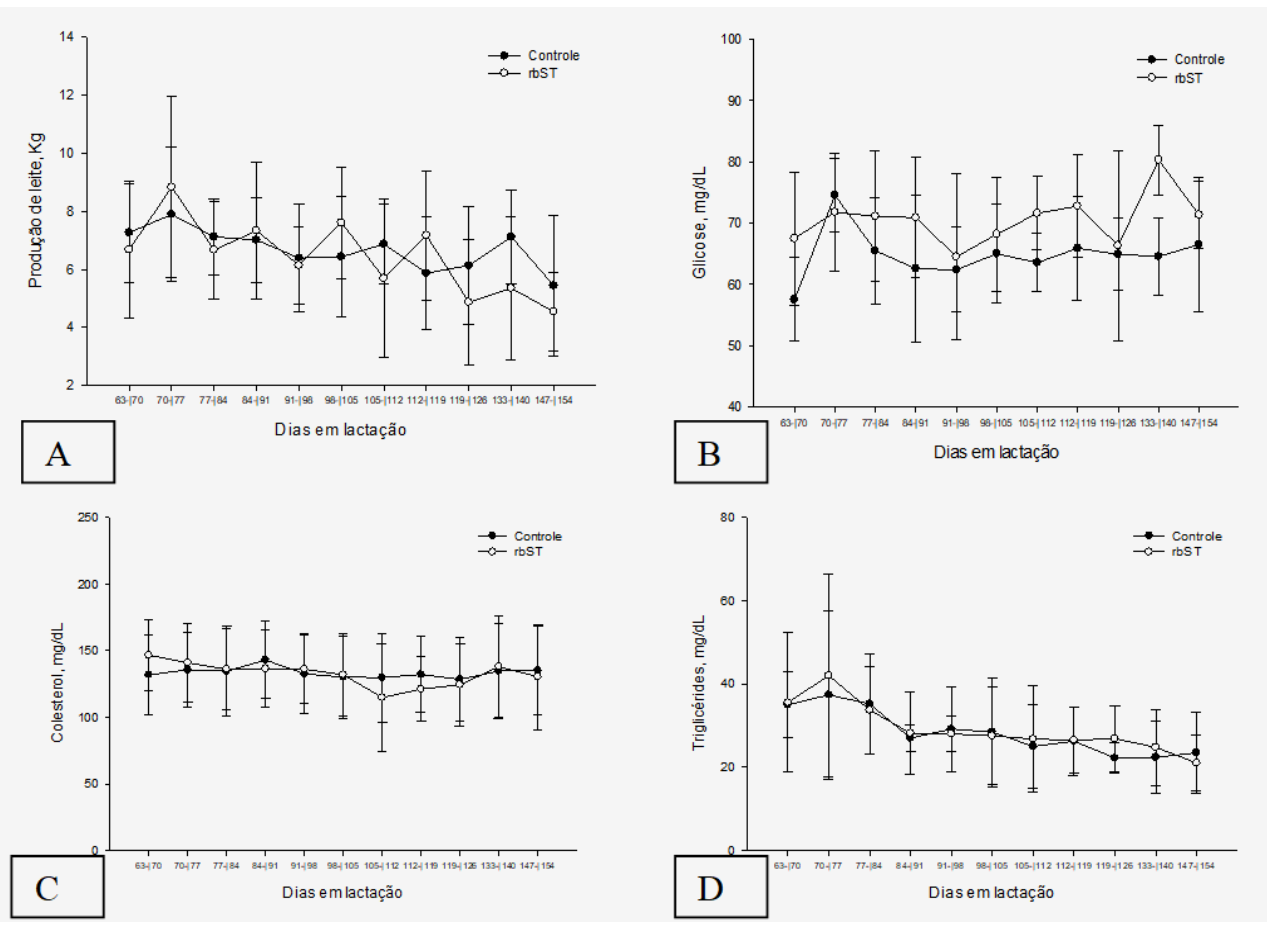

Figura 1. Produção de leite $(\mathrm{kg})$ e metabólitos sanguíneos energéticos de búfalas ao longo da lactação, que foram tratadas com somatotropina recombinante bovina (rbST) ou não (controle). Painel A produção de leite $(\mathrm{kg})$; Painel B - glicose $(\mathrm{mg} / \mathrm{dL})$; Painel C -colesterol (mg/dL); Painel D - triglicérides $(\mathrm{mg} / \mathrm{dL})$.

Durante a lactação inicial, a glicose é utilizada quase exclusivamente pela glândula mamária (com exceção do cérebro) e o aumento da produção de leite é fortemente dependente do acréscimo da oferta de glicose para a glândula (Gülaye Hatipoglu, 2005). Sob efeito desse fármaco, o transporte de glicose estaria bloqueado para os tecidos periféricos, condição conhecida como atividade diabetogênica, o que resultaria em maior quantidade líquida de glicose na circulação (Amorim et al., 2007).Embora tenha ocorrido um aumento nos níveis de glicose plasmática nas búfalas submetidas ao tratamento com $500 \mathrm{mg}$ de rbST, observou-se que este aumento da glicose não foi suficiente para refletir em uma maior produção de leite,possivelmente devido aoutros fatores ligados a genética e nutrição dos animais.

Os níveis de lipídeossanguíneos estão correlacionados com a produção leiteira das búfalas,em que, de acordo com Monteiro et al. (2012), o teor máximo de colesterol plasmático foi observado entre 60 e 200 dias de lactação, diminuindo juntamente com a produção de leite; já os teores de triglicerídeos apresentaram correlação negativa $(\mathrm{r}=-0,60 ; \mathrm{P}<0,0001)$ com a produção do leite e o rendimento da gordura láctea. Assim, os níveis desses metabólitos sanguíneos estão ligados diretamente com as exigências nutricionais para o aumento da produção de leite em búfalas. 
Para atender essa crescente demanda energética para produção de leite nos animais em balanço energético negativo (BEN), a somatotropina recombinante bovina estimula o aumento da mobilização de reservas de energia corporal (lipólise) aumentando os níveis plasmáticos de triglicérides e colesterol (Mishra e Shukla, 2004; Chaiyabutret al.,2008).Dessa forma, possivelmente a não alteração nas concentrações plasmáticas de colesterol e triglicérides em búfalas tratadas com rbST se deve ao fato de que os animais estavam em balanço energético positivo. Além disso, o aumento na produção de leite entre o grupo rbST e o controle não foi significativo. Portanto, não houve necessidade de mobilização das reservas energéticas corporais para incremento desses metabólicos, o que
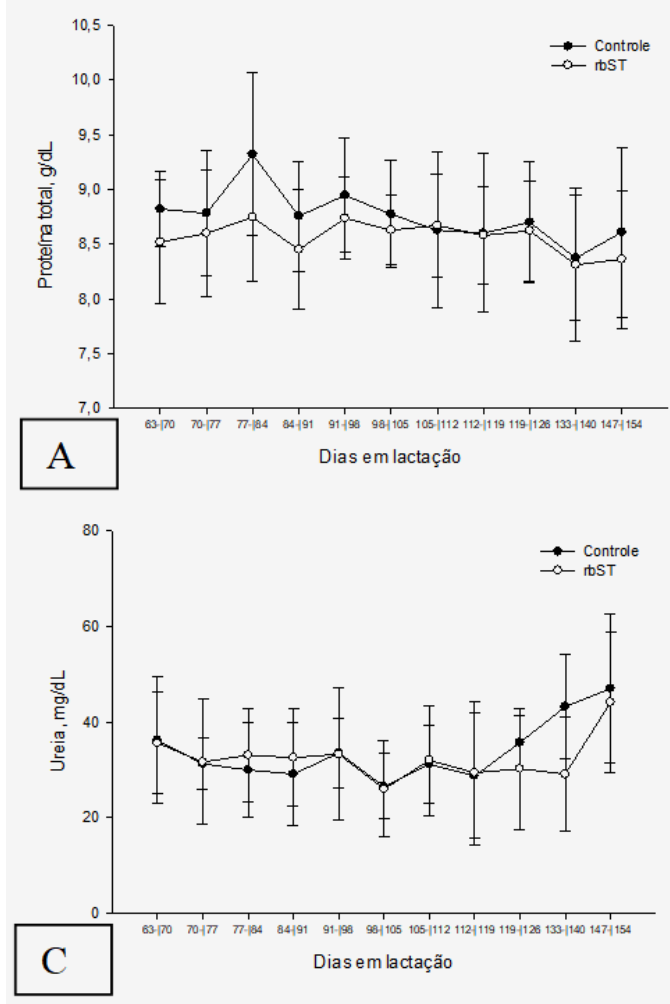

corrobora os resultados do ECC da presente pesquisa,o qual também não foi influenciado pela administração da somatotropina bovina.

Não foi observada qualquer influência darbST sobre a concentração plasmática dos metabólitos proteicos sanguíneos estudados. Durante o período do experimento, os teores de proteína total (Fig.2; Painel A), albumina (Fig.2; Painel B); ureia (Fig.2; Painel C) e creatinina (Fig.2; Painel D) no grupo tratado com 500mg de rbST ao longo da lactação variaram entre 8,31 e $8,75 \mathrm{~g} / \mathrm{dL} ; 3,16$ e $3,74 \mathrm{~g} / \mathrm{dL} ; 26,00$ e $44,13 \mathrm{mg} / \mathrm{dL}$; e 1,15 e $1,36 \mathrm{mg} / \mathrm{dL}$, enquanto no grupo controle, oscilaram entre 8,37 e $9,32 \mathrm{mg} / \mathrm{dL} ; 3,41$ e $4,01 \mathrm{mg} / \mathrm{dL} ; 26,55$ e $47,00 \mathrm{mg} / \mathrm{dL} ;$ e 1,31 e $1,52 \mathrm{mg} / \mathrm{dL}$, respectivamente.

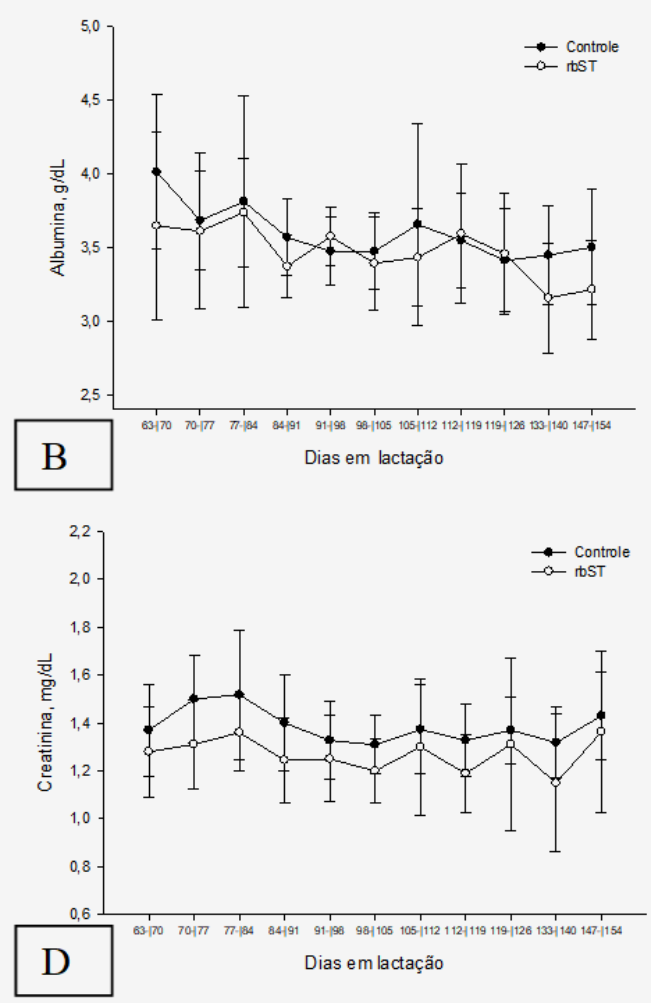

Figura 2. Metabólitos sanguíneos proteicos de búfalas ao longo da lactação, que foram tratadas com somatotropina recombinante bovina (rbST) ou não (controle). Painel A - proteína total (g/dL); Painel B albumina (g/dL); Painel C -ureia (mg/dL); Painel D -creatinina (mg/dL).

Outros estudos também não verificaram alterações nos teores de proteína total (Mishra e Shukla, 2004; Jabbaret al., 2007; Kachiwalet al., 2015), albumina (Mishra e Shukla, 2004; Helal e Lasheen, 2008; Khattabet al., 2008) e ureia (Helale Lasheen, 2008; Khattabet al., 2008) em búfalas, e creatinina (Abdelrahmanet al., 2010) em vacas,em função da administração de rbST.Em contraponto, Helal e Lasheen (2008) e Khattabet al. (2008) observaram aumento dos níveis de proteína total em búfalas tratadas com somatotropina bovina; já Abdelrahmanet al.(2010) relataram diminuição nos teores de ureia plasmática em vacas. 
Para aumentar a proteína do leite, é necessário aminoácido ou nitrogênio não proteico (NNP). Uma das ações fisiológicas clássicas da somatotropina é a sua habilidade em promover a conservação de nitrogênio. Ela reduz a taxa de renovação da proteína muscular e a oxidação de aminoácidos para produção de energia, de modo que existam mais aminoácidos disponíveis para a síntese de proteínas do leite e a síntese de proteína muscular, levando à redução dos níveis séricos de ureia e creatinina (Rangel et al., 2008). Dessa forma, possivelmente, essa não alteração no metabolismo proteico das búfalas tratadas com rbST se deve ao fato de que não houve aumento significativo na produção de leite nem alteração do ECC. Assim, não houve um acréscimo nas necessidades de aminoácidos para produção de proteína láctea e de energia via gliconeogênese para a síntese do leite.

Não foi observada qualquer influência darbST sobre a concentração sérica dos metabólitos minerais sanguíneos estudados. Durante o período do experimento, os teores de cálcio (Fig.3; Painel B), fósforo (Fig.3; Painel C) emagnésio (Fig.3; Painel D)no grupo tratado com 500mg de rbST ao longo da lactação variaram entre 9,26 e $11,95 \mathrm{mg} / \mathrm{dL} ; 5,16$ e $6,15 \mathrm{mg} / \mathrm{dL}$; e 61 e $3,79 \mathrm{mg} / \mathrm{dL}$, enquanto, no grupo controle, oscilaram entre 9,93 e $11,84 \mathrm{mg} / \mathrm{dL} ; 5,27$ e 6,32mg/dL; e3,60 e $3,78 \mathrm{mg} / \mathrm{dL}$, respectivamente, corroborando os estudos de Deshmukhiet al. (2001), que também não observaram alterações nos teores desses metabólitos em função da administração de rbST em vacas leiteiras, e de Jabbaret al. (2007) eKachiwalet al.(2015) nos teores de cálcio sérico. Em contraponto, Abdelrahmanet al. (2010) encontraram uma diminuição significativa no nível de cálcio, acompanhada de um aumento no fósforo em vacas multíparas tratadas com somatotropina.

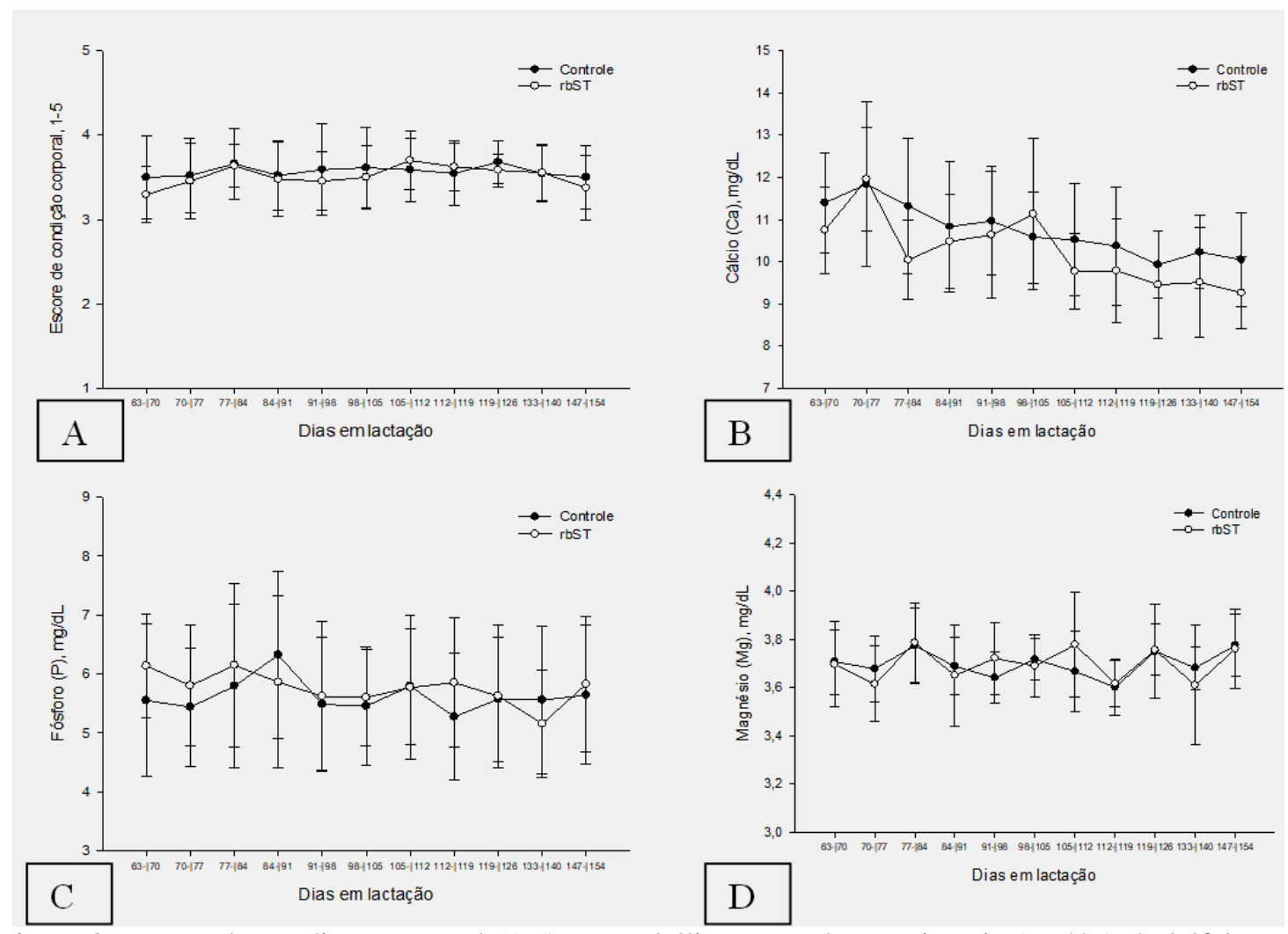

Figura 3. Escore de condição corporal (1-5) e metabólitos sanguíneos minerais (mg/dL) de búfalas ao longo da lactação, que foram tratadas com somatotropina recombinante bovina (rbST) ou não (controle). Painel A - escore de condição corporal (1-5); Painel B - cálcio (mg/dL); Painel C -fósforo (mg/dL); Painel D -magnésio (mg/dL). 
De acordo comPeel e Bauman (1987),entre as mudanças que ocorrem na absorção e mobilização de minerais no organismo, ao se utilizar rbST, observa-se maior absorção e ou mobilização de $\mathrm{Ca}$ e $\mathrm{P}$ e outros minerais requeridos para a produção de leite. Dessa forma, possivelmente essa não alteração no metabolismo dos minerais das búfalas tratadas com rbST, no presente estudo, deve-se ao fato de que não houve aumento significativo na produção de leite, portanto não houve um acréscimo nas necessidades de cálcio, fósforo e magnésiopara a síntese do leite.

\section{CONCLUSÃO}

O uso de 500mg de rbST é capaz de modular o metabolismo da glicose de búfalas leiteiras criadas a pasto.No entanto, esse tratamento não modificou os níveis dos demais metabólicos energéticos (colesterol e triglicérides), protéticos (proteína total, albumina ureia e creatinina) e minerais (cálcio, fósforo e magnésio), tampouco a produção de leite e o escore de condição corporal em búfalas leiteiras criadas a pasto.

\section{REFERÊNCIAS}

ABDELRAHMAN, A.H.; KHALIL, A.S.; ELHAMAMSY, H.T.; EZZO, O.H. The effect of recombinant bovine somatotropin administration on milk production, some hemato-biochemical parameters and reproductive performance of lactating cows. Global Vet., v.4, p.366-373, 2010 .

AMORIM, L.S.; TORRES, C.A.A.; MORAES, E.A.; SILVA FILHO, J.M.; GUIMARÃES, J.D. Perfil metabólico de touros da raça Nelore (Bostaurusindicus) confinados e tratados com somatotrofina bovina recombinante (r-bST). Arq. Bras. Med. Vet. Zootec., v.59, p.434-442, 2007.

AZEVEDO, J.C.; SANTOS, E.R.D.; MENDES NETO, L.O.R. et al. Produção de leite no dia do controle de búfalas leiteiras no estado do Pará. In: CONGRESSO INTERNACIONAL DE ZOOTECNIA ZOOTEC, 13., 2011, Maceió. Anais... Maceió: [s.n], 2011. p.1-3. (Resumo).

BAUMAN, D.E. Bovine somatotropin: review of an emerging animal technology. J. Dairy Sci., v.75, p.3432-3451, 1992.
CASTIGLIEGO, L.; LI, X.N.; ARMANI, A. et al. Hormone variations in serum and milk of buffaloes (Bubalusbubalis) as potential indicators of treatment with recombinant bovine somatotropin. J. Dairy Sci., v.78, p.412-420, 2011.

CHAIYABUTR, N.; THAMMACHAROEN, S.; KOMOLVANICH, S.; CHANPONGSANG, S.Effects of long-term administration of recombinant bovine somatotropin on the concentration of metabolites in milk in different stages of lactation in crossbred Holstein cattle. Anim. Sci. J., v.79, p.41-50, 2008.

DESHMUKHI, B.T.; NAGVEKAR, A.S.; TALVELKARJ, B.A. et al.Effect of bovine somatotropin on blood serum minerals, thyroid hormones and reproductive performance of lactating crossbred cows. Indian J. Anim. Sci., v.71, p.663-666, 2001.

FECKINGHAUS, M.A. Influência da aplicação da somatotropina recombinante bovina (rbST) no lipidograma e composição do leite de bubalinos da raça Murrah em lactação. 2009. 89f. Dissertação (Mestrado em Clínica Veterinária) - Universidade de São Paulo, São Paulo, SP.

GÜLAY, M.S.; HATIPOGLU, F.S. Use of bovine somatotropin in the management of transition dairy cows. Turk. J. Vet. Anim. Sci., v.29, p.571-580, 2005.

HELAL, F.I.S.; LASHEEN, M.A. The productive perforance of egyptian dairy buffaloes receiving biosynthetic bovine somatotropin (rbST) with or without monensin. Am. Eurasian J. Agricul. Environ. Sci., v.3, p.771-777, 2008.

HOUGHTON, P.L.; LEMENAGER, R.P.; HORSTMAN, L. et al. Effects of body composition, pre and pospartum energy level and early weaning on reproductive performance of beef cows and preweaning calf gain.J. Anim. Sci., v.68, p.1438-1446, 1990.

JABBAR, M.A.; AHMAD, I.; JAVID, S. et al. Effect of bovine somatotropic hormone on the productive performance of Nili-Ravi buffaloes.Ital. J. Anim. Sci., v.6, p.1039-1042, 2007. 
JORGE, A.M.; GOMES, M.I.F.V.; HALT, R.C. Efeito da utilização da somatotropina bovina recombinante (bST) sobre a produção de leite em búfalas. Rev. Bras. Zootec., v.31, p.1230-1234, 2002.

KACHIWAL, A.B.; SHEIKH, B.A.; SHEIKH, S.A. et al. Effect of rbST on serum biochemical values during various physiological and weather conditions in kundhi buffaloes. J. Buff. Sci., v.4, p.1-9, 2015.

KHAN, H.M.; MOHANTY, T.K.; BHAKAT, M. et al. Relationship of blood metabolites with reproductive parameters during various seasons in Murrah buffaloes. Asian-Aust.J. Anim. Sci., v.24, p.1192-1198, 2011.

KHATTAB, H.M.M.; EL-SAVED, H.M.; ABO EL-NOR, S.A.H. et al. Impact of bovine somatotropin and monensin on the productive performance of Egyptian dairy buffaloes. $J$. Dairy Sci., v.3, p.11-19, 2008.

LANNA, D.P.D.; HOUSEKNECHT, K.L.; HARRIS, D.M.; BAUMAN, D.E. Effects of somatotropin treatment on lipogenesis, lipolysis, and related cellular mechanisms in adipose tissue of lactating cows. J. DairySci., v.78, p.17031712, 1995.

MELO, W.O.; VIANA, R.B.; MONTEIRO, B.M. et al. Produção e composição do leite de búfalas tratadas com somatotropina recombinante bovina no pico de lactação. Acta Vet. Bras., v.7, p.218-228, 2013.

MISHRA, A.; SHUKLA. Effect of recombinant bovine somatotropin (Boostin-250) on blood metabolites and milk yield of lactating buffaloes. Asian-Australas. J. Anim. Sci., v.17, p.12321235, 2004.
MONTEIRO, B.M.; YASUOKA, M.M.; POGLIANI, C. et al. Lipid and glucose profiles of dairy buffaloes during lactation and dry period. Rev. Cienc. Agrar., v.55, p.33-39, 2012.

PEEL, C.J.; BAUMAN, D.E. Somatotropin and lactation. J. Dairy Sci., v.70, p.474-486, 1987.

PEIXOTO, L.A.O.; OSÓRIO, M.T.M. Perfil metabólico proteico e energético na avaliação do desempenho reprodutivo em ruminantes. Rev. Bras. Agrociênc., v.13, p.299-304, 2007.

PRASAD, J.; SINGH, M. Milk production and hormonal changes in Murrah buffaloes administered recombinant bovine somatotropin (rbST). Agric. Biol. J. N. Am., v.1, p.1325-1327, 2010.

RANGEL, A.H.N.; DIVINO, M.R.; LEONEL, F.P.; LIMA JÚNIOR, D.M. Somatotropina na pecuária de leite. Pubvet, v.2, p.1982-1263, 2008.

RODRIGUES, M. Impacto da utilização da somatotropina bovina (bST) sobre a produção de leite e a avaliação genética de bovinos da raça Holandesa. 2008. 59f. Dissertação (Mestrado em Ciências Biológicas) - Faculdade de Medicina de Ribeirão Preto, Universidade de São Paulo, SP.

SANTOS, R.A.; TEIXEIRA, J.C.; ABREU, L.R. et al. Efeito de diferentes doses de somatotropina bovina (rBST) na produção e composição do leite.Ciênc. Agrotec., v.25, p.1435-1445, 2001.

SILVA, D.J.; QUEIROZ, A.C.Q. Análise de alimentos: métdos químicos e biológicos. 3.ed. Viçosa, MG: UFV, 2002. 235p.

STATISTICAL analysis system. Versão 9.2. Cary: SAS Institute, 2008. 